\title{
STUDY ON FLEXURAL BEHAVIOUR OF RC BEAMS STRENGTHENED WITH BFRP LAMINATES
}

\author{
RAJASEKARAN. A \& KESAVAN. S \\ Professor, Annamalai University, Chidambaram, Tamil Nadu, India
}

Research Scholar, Department of Civil \& Structural Engineering, Annamalai University,

Chidambaram, Tamil Nadu, India

\begin{abstract}
Strengthening of concrete elements by externally bonded Fiber Reinforced Polymer (FRP) sheets is becoming very popular worldwide during the past decade. Since it results in better economic consideration and immediate shelter to problems rather than replacement of whole existing structure. Many researchers have been conducted for enhancing the flexural behavior of reinforced concrete beam strengthened with FRP reinforcement under monotonic static loads. However, any structure will be subjected to cyclic load that arise due to the dynamic action of seismic force, wheel loads, impact load etc., in such cases, retrofitting should be effective under cyclic flexural actions. Studies under cyclic load actions are very limited and this paper focuses on the research gap of BFRP laminated beam. In this paper, an experimental investigation is carried out to study the behavior of simply supported reinforced concrete beam under cyclic load. The beams are externally strengthened by bonding of Basalt Fiber Reinforced Polymer (BFRP) sheets. The study consists of two beams, a controlled beam and a beam strengthened with three layers of BFRP sheets. All the beams have the same dimension of $150 \mathrm{~mm}$ wide, $250 \mathrm{~mm}$ deep and $3000 \mathrm{~mm}$ span. The present study examines the response of flexural behavior of beams in terms of enhancing the load carrying capacity and loaddeflection analysis. The results indicated that the flexural strength of the reinforced concrete beam can be significantly increased by the bonding of BFRP sheets at its soffit. In addition, it also results in improved ductility and stiffness of the beam element at higher load levels.

KEYWORDS: Basalt Fiber, Resin, Reinforced, Ductility, Stiffness
\end{abstract}

Received: Jun 08, 2020; Accepted: Jun 28, 2020; Published: Aug 21, 2020; Paper Id.: IJMPERDJUN2020851

\section{INTRODUCTION}

Strengthening is a process of upgrading the certain structural components to make them more resistant against unexpected load. It is recommended for the existing structure deteriorates or any alteration to the structure has to be made due to the structural failure. It can be provided in the form of concrete jacketing, bonding steel plate, caging of steel section, grouting, section enlargement, addition of new members (shear wall, bracing, and buttress), etc., [1]

An advanced new technique has emerged recently by using fiber reinforced polymer sheet to strengthen the structural components [2]. Fiber Reinforced Polymer (FRP) is defined as "a matrix of polymeric material that is reinforced by fibers". FRP sheets can be wrapped over the structural components providing an economical and technically a best alternative to all other traditional methods of strengthening [3,4]. Fiber reinforced polymer is a composite material in which the polymer is reinforced with high strength fibers. The fiber act as a reinforcement which carries the load along the length of the fiber, strength and stiffness of the concrete element. FRP is a flat layer of polymer with an arrangement of unidirectional fiber fabrics embedded within a thin layer of light polymer matrix material using resin [5,6]. The primary function of fiber is to carry load along the length of the fiber which 
provides strength and stiffness in one direction. Resign is used to transfer stress between reinforcing fibers and to protect them from mechanical and environmental damage. The fibers normally used are carbon, glass or aramid and the resins can be of epoxy, polyester or vinyl ester. It can be used to strengthen beam, column, and slab in buildings and girders in bridges. When the FRP specimen is loaded axially, it behaves linear-elastic and the behavior of FRP is relative to proportion for volume of fibers, the properties of the fiber and resin, and the interface bond strength. During the transverse loading, the FRP's response is very much dependent on the properties of the fiber and matrix, its interaction and the strength of the fiber matrix interface [7].

In this study, basalt fiber called the green industrial material is used for strengthening of reinforced concrete beam. Basalt fibers are obtained from igneous basalt rock and it is made up of $100 \%$ natural [8]. Basalt fibers \& fabrics are labeled as safe according to both the USA and the European occupational safety guidelines. Basalt as a fiber used in FRPs has high potential and getting a lot of attention due to its high temperature and abrasion resistance compared with all other fibers. Basalt rocks are melted at $14501500^{\circ} \mathrm{C}$ in a crucible chamber to produce continuous filaments and are gathered into a single strand of fiber $[9,10]$. The present study is to carry out an experimental investigation of externally bonded simply supported beam using BFRP sheets. This work consists of two beams, one: controlled beam made of M20 grade and the other strengthened with three layers of BFRP sheets at its soffit. The flexural behavior of both the beams are studied under cyclic loading and concluded by comparison is obtained from the test results.

\section{EXPERIMENTAL INVESTIGATION}

\subsection{Materials Used}

Properties of concrete are influenced by many factors mainly due to mix proportion of cement, sand, aggregates and water. The qualities of the material are tested to attain the target strength of the concrete.

\subsubsection{Cement}

The cement is widely used in the construction of various engineering structures. Ordinary Portland cement are always recommended for the research work. Hence ordinary Portland cement 53 grade are used in this research due to the absence of pozzolana material. The initial setting time of ordinary Portland cement is 33minutes and it is depend on the fineness of cement, cement-water ratio, chemical content, and admixtures. The specific gravity of the cement is generally used in the mix proportion calculation. Ordinary Portland cement of 53 grades has a specific gravity of 3.15. The consistency of cement is checked with vicat apparatus and it attains $30 \%$ of standard consistency.

\subsubsection{Fine Aggregate}

Fine aggregate content is usually $35 \%$ to $45 \%$ by the total volume of aggregate content. Locally available river sand are used as fine aggregate in this research. This river sand has a density of $1600 \mathrm{~kg} / \mathrm{m} 3$ and it is depend upon the fineness modulus value. The fineness modulus is calculated with standard sieves and it has a value of 3.11. The river sand is confirming the zone II as per IS 3831987 and the specific gravity is 2.73 .

\subsubsection{Coarse Aggregate}

Natural gravel is washes and used as a coarse aggregate in the concrete. The fineness modulus is the index of the fineness of coarse aggregate as 8 . Nominal grain size of $20 \mathrm{~mm}$ are used to occupy the proper space between the reinforcements. The specific gravity value of coarse aggregate is 2.89 and it is used to calculate the mass of aggregate in the mix proportion. The water absorption of coarse aggregate is $0.56 \%$ and it tends to represent the voids content of aggregate. 


\subsubsection{Water}

The quantity of water is used to determine the water to cementations material ratio of concrete mixture. The quality of water is adversely affected the strength and durability of concrete. The portable tap water is used for the mixing and curing of specimen.

\subsubsection{Basalt Fiber Reinforced Polymer}

BFRP is a composite material made of polymer matrix reinforced with the basalt fiber. Basalt fiber is manufactured by melting the basalt rock of about $1500^{\circ} \mathrm{C}$ and the sheets are made with unidirectional arrangement of basalt fiber. Coupon test is conducted and determined the tensile strength of BFRP sheet as 1678MPa. The main advantage of using BFRP sheet for its modulus of elasticity and it has a value of about 20387MPa. The thickness of BFRP sheet is $0.33 \mathrm{~mm}$ and it is wrapped up to three layers in the beam.

\subsection{Test Specimen Preparation}

The controlled (CC) and strengthened (BFRP) reinforced concrete beams are tested and it is made up of rectangular cross section with $150 \mathrm{~mm}$ width and $250 \mathrm{~mm}$ depth spanning over $3000 \mathrm{~mm}$. It consists of 2 no's of $12 \mathrm{~mm}$ diameter in its tension phase and 2 no's of $10 \mathrm{~mm}$ diameter in its compression phase with $8 \mathrm{~mm}$ diameter stirrups at $125 \mathrm{~mm} \mathrm{c} / \mathrm{c}$. Figure 1 depicts the reinforcement detailing of the beam specimen.

The M20 grade concrete mix is prepared with a proportion of 1:1.89:3.56 of cement, fine aggregate and coarse aggregate. The mixing is done using a concrete mixer by adding a required amount of water and placed over the wooden beam mould as shown in Figure 2.

Proper vibration is done to remove the entrapped air bubbles and the casted specimen is kept undisturbed for 24 hours. Then the beam is remolded and cured for 28 days to reach its strength.
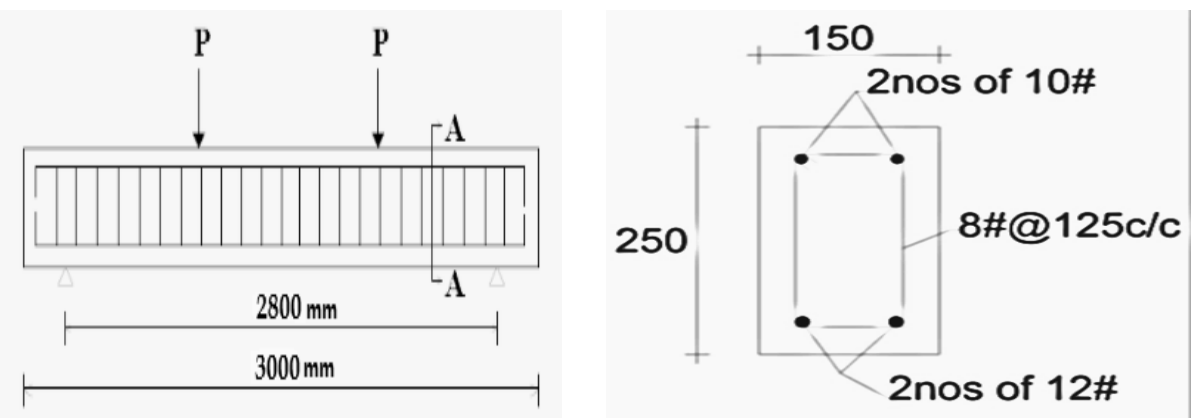

Figure 1: Reinforcement Detailing of Beam Specimen.

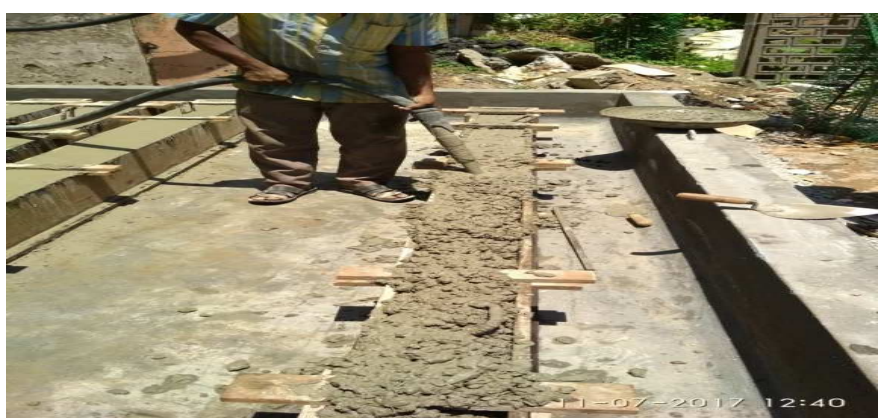

Figure 2: Casting of Beam Specimen with Proper Vibration. 


\subsection{Strengthening of Beam}

Basalt fabric of thickness $0.41 \mathrm{~mm}$ with density $2.67 \mathrm{~g} / \mathrm{cc}$ is used for strengthening purpose. The resin and hardener are used for the fabrication of Epoxy resin (COROCRETE) and Polyamine respectively. The chemical reaction of the resin hardens the material to a strong light weight product. The strengthening process begins with soffit roughening using coarse sand paper texture and it is cleaned from dirts and debris for better bonding of beam with BFRP sheet. The fabrics are cut into the required dimension and three layers of fabrics are attached together by using epoxy resin.

For $1 \mathrm{~kg}$ of resin, $200 \mathrm{gm}$ of hardener is used and the mixing is carried out in a plastic container. After uniform mixing, the resin is applied uniformly at the soffit of the concrete beam. The BFRP plate is then placed on top of the resin coating and the excess resin are wiped off by rolling a steel roller over it. Placing of FRP sheet on beam specimen are shown in the Figure 5.

This whole strengthening process is carried out at room temperature and it is cured in open atmosphere for about 7 days before testing as shown in Figure 6 .

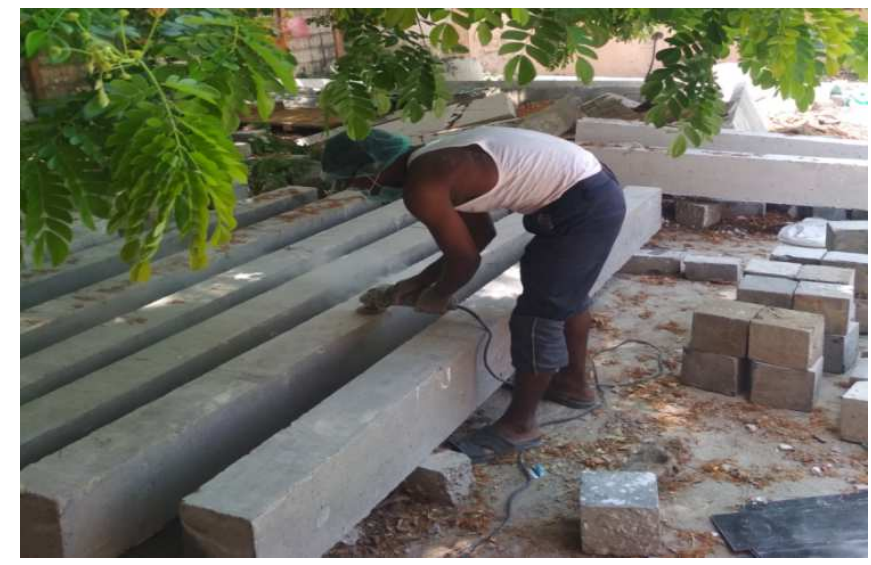

Figure 3: Surface Preparations for Strengthening.

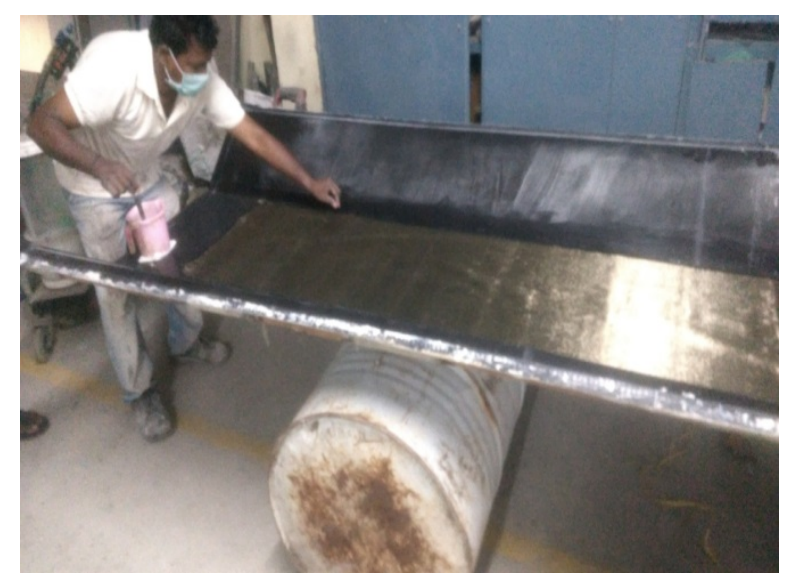

Figure 4: Preparation of BFRP Sheet. 


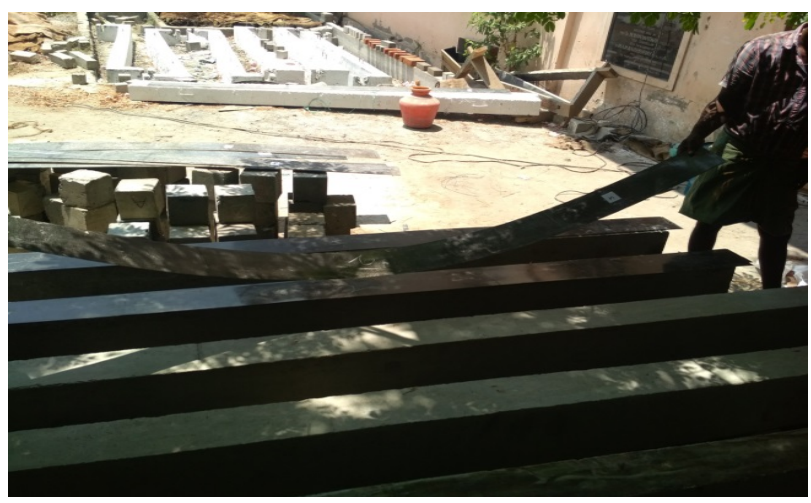

Figure 5: Placing of BFRP Sheet on Beam Specimen.

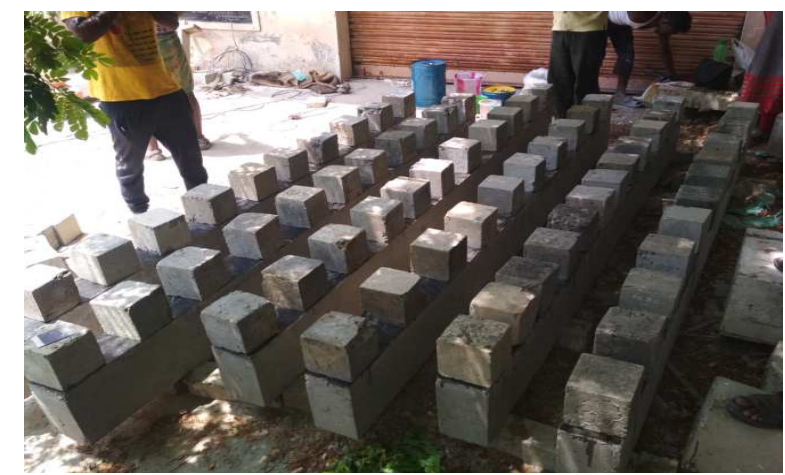

Figure 6: Curing of BFRP Strengthened Beam.

\subsection{Test Setup}

The beams are tested in Structural Engineering Laboratory of Annamalai University, Chidambaram. Figure 7 depicts the experimental setup for the testing of beam specimen.

The two-point cyclic load test is carried out and the testing procedure is same for both the beams. The specimen is simply supported over the two steel rollers with a bearing of $100 \mathrm{~mm}$ from ends of the beam. The remaining span is divided into equal parts for uniform application of load. The load is transmitted through the load cell uniformly by means of spreader beam. Deflection of the beam can be read from LVDT which is placed at the soffit of beam. The load is applied in cyclic mode and each increment of $10 \mathrm{kN}$ is considered as one cycle. The load cell initially at $0 \mathrm{kN}$ is gradually increased and deformations are recorded throughout the test with each increment of $10 \mathrm{kN}$ load. This cyclic process continues till the ultimate failure of beam is reached.

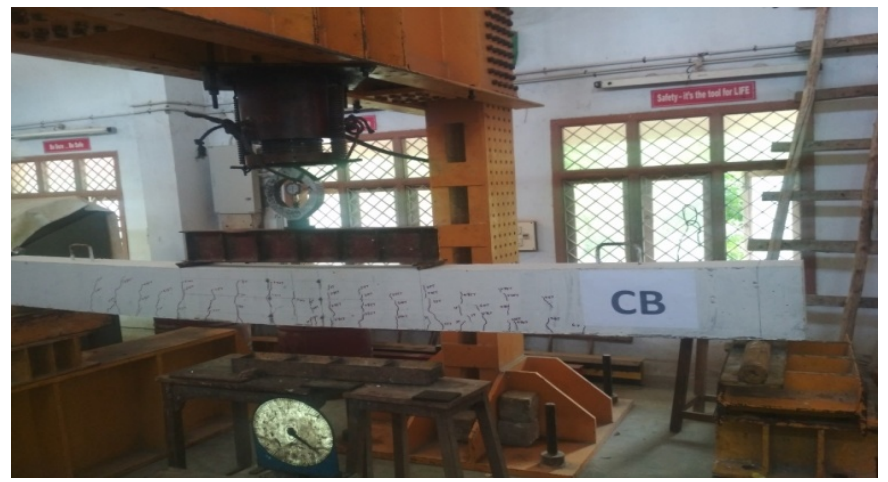

Figure 7: Experimental Setup for Beam Testing. 


\section{RESULTS AND DISCUSSIONS}

\subsection{Load-Deflection}

The two-point cyclic load test is performed on the controlled and strengthened beam by using BFRP laminates. Beam element is displaced with the increasing flexural load and it is noted for each cycle of load. The load deflection behavior of beams is plotted with loads on vertical axis and its deflection on horizontal axis as graphed in Figure 8.

It is evident from the above graph, the ultimate load carrying capacity of BFRP beam is found to be $40 \mathrm{kN}$ which is enhanced by $8.1 \%$ than the controlled beam. On the other hand, the deflection is minimized by $12.26 \%$ in comparison to controlled concrete beam.

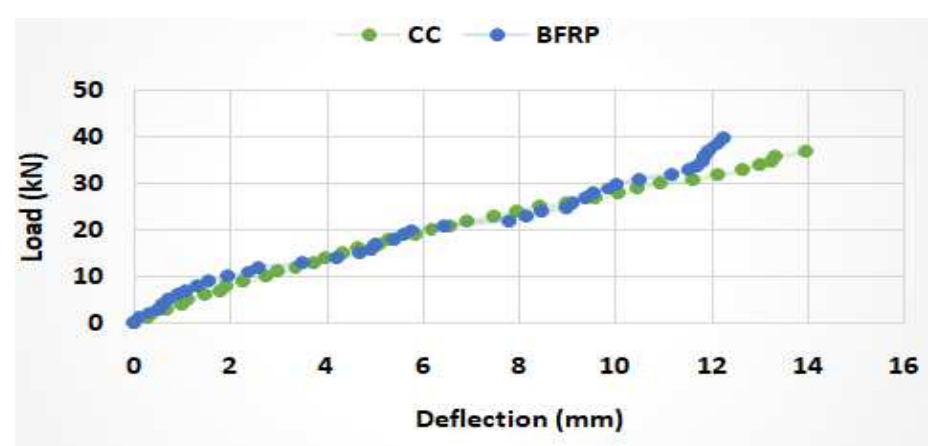

Figure 8: Load-Deflection Behaviors for CC and BFRP Beams.

\subsection{Moment-Curvature}

Moment curvature is an important factor to find the ductility ratio of concrete beam. Moment curvature calculation denotes the moment of resistance at section and its corresponding curvature.

Figure 9 traces the moment-curvature plot for controlled and the strengthened beam. The ultimate moment carrying capacity and bending curvature of controlled concrete beam is $17.27 \mathrm{kNm}$ and $14.235 \times 10^{-6} / \mathrm{m}$ respectively. On inclusion of BFRP with 3 Layer, enhanced the moment carrying capacity by $8.1 \%$ and the curvature by $12.26 \%$ than the controlled concrete beam.



Figure 9: Moment-Curvature Behavior for CC and BFRP Beams.

\subsection{Ductility}

Ductility indicates the ability of beam element undergoes the deformation before reaches it failure stage. The BFRP layered beam significantly increased the ductility index and provided the signs of failure. Table 1 and 2 tabulates the ductility and stiffness value for CC and BFRP beam respectively. 
The ductility factor for controlled concrete beam and BFRP beam is found to be 1.836 and 2.8 respectively. It showed that the ductility of BFFP strengthened beam is 1.53 times the controlled concrete beam. From Figure 10, it is clear that the CC beam withstand load till third cycle whereas the BFRP beam extended the resistance to bending up to fourth cycle.

Table 1: Ductility and Stiffness value for CC Beam

\begin{tabular}{|c|c|c|c|c|c|}
\hline Cycle No & $\begin{array}{c}\text { Ultimate } \\
\text { Load (kN) }\end{array}$ & $\begin{array}{c}\text { Maximum } \\
\text { Deflection (Mm) }\end{array}$ & $\begin{array}{c}\text { Ductility } \\
\text { Factor }\end{array}$ & $\begin{array}{c}\text { Cumulative } \\
\text { Ductility Factor }\end{array}$ & $\begin{array}{c}\text { Stiffness } \\
(\mathbf{k N} / \mathbf{M m})\end{array}$ \\
\hline 1 & 10 & 2.24 & 0.188 & 0.188 & 4.46 \\
\hline 2 & 20 & 7.63 & 0.640 & 0.828 & 2.62 \\
\hline 3 & 30 & 12.02 & 1.008 & 1.836 & 2.50 \\
\hline
\end{tabular}

Table 2: Ductility and Stiffness value for BFRP Beam

\begin{tabular}{|c|c|c|c|c|c|}
\hline Cycle No & $\begin{array}{c}\text { Ultimate } \\
\text { Load }(\mathbf{k N})\end{array}$ & $\begin{array}{c}\text { Maximum } \\
\text { Deflection }(\mathbf{M m})\end{array}$ & $\begin{array}{c}\text { Ductility } \\
\text { Factor }\end{array}$ & $\begin{array}{c}\text { Cumulative } \\
\text { Ductility Factor }\end{array}$ & $\begin{array}{c}\text { Stiffness } \\
(\mathbf{k N} / \mathbf{M m})\end{array}$ \\
\hline 1 & 10 & 1.96 & 0.170 & 0.170 & 5.10 \\
\hline 2 & 20 & 7.36 & 0.638 & 0.808 & 2.72 \\
\hline 3 & 30 & 10.75 & 0.932 & 1.739 & 2.79 \\
\hline 4 & 40 & 12.24 & 1.061 & 2.800 & 3.27 \\
\hline
\end{tabular}

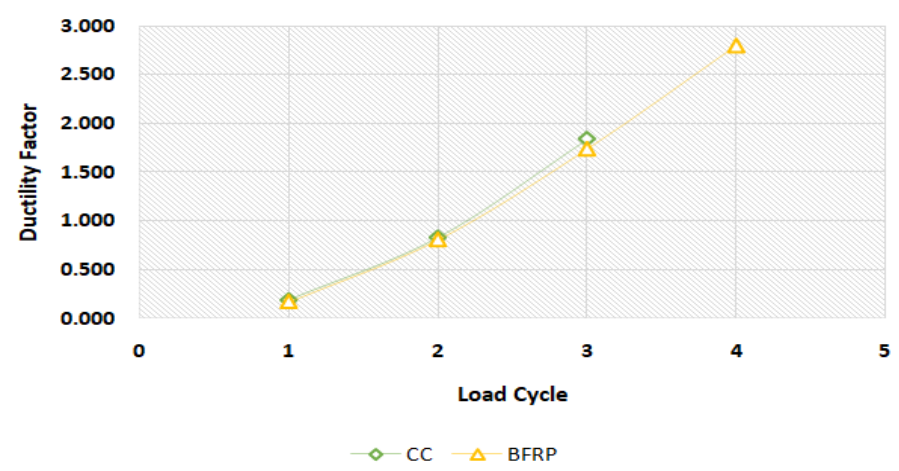

Figure 10: Variation in Ductility Factor with Load Cycle for CC and BFRP Beams.

\subsection{Stiffness}

Stiffness of the beam is calculated and it is proved that the resistance to deformation is increased in BFRP beams. Figure 11 illustrates the variation of stiffness of CC and BFRP beam along the load cycles. The stiffness value for BFRP beam is increased by 1.31 times the $\mathrm{CC}$ beam.

The comparison of stiffness and ductility value for controlled concrete beam \& BFRP beams are displayed in Figure 12.

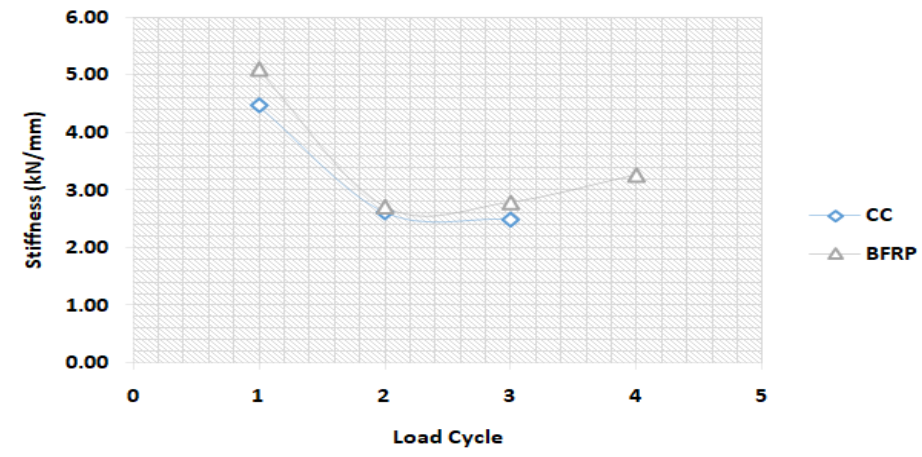

Figure 11: Variation of Stiffness with Load Cycle for CC and BFRP Beams. 




Figure 12: Comparison of Stiffness and Ductility value for $\mathrm{CC}$ and BFRP Beams.

\section{CONCLUSIONS}

The two-point cyclic load test is conducted and the findings of the present study are validated for the flexural behavior of reinforced concrete beam strengthened three layers of BFRP sheets at the soffit of the beam in comparison with the controlled concrete beam. In this respect, the following conclusions are obtained:

- Inclusion of BFRP sheets for the strengthening of reinforced concrete beam enhanced the load and moment carrying capacity by $8.1 \%$ compared with controlled concrete beam. Correspondingly, the deflection and curvature of beam is minimized by $12.26 \%$ than controlled beam.

- The crack patterns of the beam are concluded that the number of cracks for strengthened beam is high compared to the controlled concrete beam.

- The ductility and stiffness of the BFRP beam is improved by 1.53 times and 1.31 times the CC beam.

- Therefore, from the above obtained results, the provision of basalt fiber in the form of sheets exhibited an improved flexural behavior under the two-point cyclic load.

\section{REFERENCES}

1. G E Thermou, A S Elnashai (2005), 'Seismic retrofit schemes for RC structures and local $\square$ global consequences', Earthquake Engineering and Structural Dynamics, Progress in Structural Engineering and Materials.

2. Priyanka Sarker et al., (2011), 'Fiber reinforced polymers for structural retrofitting: A review', Journal of Civil Engineering.

3. Al-Shammari, Mohsin Abdullah "EFFECT OF HOLE SHAPE ON FREE VIBRATION CHARACTERISTICS OF UNIDIRECTIONAL COMPOSITE PLATES." Iraqi journal of mechanical and material engineering 15.1 (2015): 3148.

4. Khalid Heiza et al. (2014), 'State-of-the Art Review: Strengthening of Reinforced Concrete Structures-Different Strengthening Techniques', Sixth International Conference on Nano-Technology in Construction.

5. Dipen Kumar Rajak et al. (2019), 'Fiber-Reinforced Polymer Composites: Manufacturing, Properties, and Applications', Polymers 2019, 11, 1667.

6. Ayesha Siddikaet al. (2019), 'Strengthening of reinforced concrete beams by using fiber-reinforced polymer composites: A review', Journal of Building Engineering 25(September):100798 · September 2019,DOI: 10.1016/j.jobe.2019.100798.

7. Al-Waily, Muhannad, et al. "Influences of Glass and Carbon Powder Reinforcement on the Vibration Response and Characterization of an Isotropic Hyper Composite Materials Plate Structure." International Journal of Mechanical \& Mechatronics Engineering IJMMEIJENS 17.06 (2017). 
8. AzadehParvin and David Brighton (2014), 'FRP Composites Strengthening of Concrete Columns under Various Loading Conditions', Polymers 2014, 6, 10401056; doi: 10.3390/polym6041040.

9. Tara Sen and Ashim Paul (2015) 'Confining concrete with sisal and jute FRP as alternatives for CFRP and GFRP', International Journal of Sustainable Built Environment, Volume 4, Issue 2, December 2015, Pages 248-264, Elsevier.

10. Raja, R., and SabithaJannet. "Experimental investigation of high speed drilling of glass fiber reinforced plastic (GFRP) composite laminates made up of different polymer matrices." Int. J. Mech. Prod. Eng. Res. Dev 7.6 (2017): 351358.

11. Dejian Shen et al. (2015), 'Dynamic Bond Stress-Slip Relationship between Basalt FRP Sheet and Concrete under Initial Static Loading', Journal of Composites for Construction 19(6):04015012 - August 2015, DOI: 10.1061/(ASCE)CC.19435614.0000568 .

12. Dogra, Aditya, AkshinaSoni, and YogeeshaPai. "An experimental study on the mechanical properties of basalt and banana fiber reinforced Hybrid polymer composites." International Journal of Mechanical and Production Engineering Research and Development 9.1 (2019): 263270.

13. ElisabettaMonaldo et al. (2019), 'Basalt-based fiber-reinforced materials and structural applications in civil engineering', Composite Structures 214:246263 - February 2019, DOI: 10.1016/compstruct.2019.02.002.

14. RavikantShrivastava et al. (2012), 'Effect of Cyclic Loading On Flexural Behaviour Of FRP Strengthened RC Beams: A Stability Point Approach ', International Journal of Advanced Research in Engineering and Applied Sciences, ISSN: 22786252. 

